\title{
Efeito de um protocolo de exercícios craniocervicais na redução da frequência $e$ intensidade das crises de migrânea em comparação ao grupo placebo - ensaio clínico randomizado
}

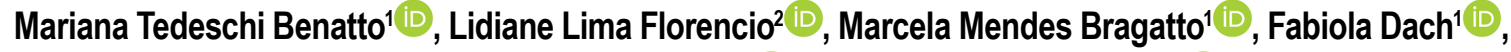 \\ César Fernández-de-las-Peñas ${ }^{2}$ iD, Débora Bevilaqua-Grossi ${ }^{1}$
}

'Faculdade de Medicina de Ribeirão Preto, Universidade de São Paulo, Ribeirão Preto, SP, Brasil

${ }^{2}$ Universidade Rey Juan Carlos, Alcorcón, Espanha

\section{Introdução}

Pacientes com migrânea apresentam alterações musculoesqueléticas e dor cervical. Por meio da fisiopatologia da doença, é possível entender a relação entre a migrânea e a coluna cervical. Entretanto, a eficácia de exercícios craniocervicais em pacientes com migrânea ainda não foi verificada.

\section{Objetivo}

Verificar a eficácia de um protocolo de exercícios crâniocervicais na redução da frequência e intensidade das crises de migrânea.

\section{Métodos}

Foi realizado um ensaio clínico randomizado com follow-up de 3 meses. O grupo intervenção $(n=21)$ realizou por 8 semanas um protocolo de exercícios craniocervicais, enquanto o grupo placebo $(n=21)$ recebeu, durante oito semanas, aplicação de ultrassom terapêutico desligado na porção média do trapézio superior. Os desfechos primários foram frequência e intensidade das crises de migrânea, verificados pelo diário de dor. Os desfechos secundários foram o desempenho muscular no craniocervical flexion test (CCFT), força e resistência cervical, associados à eletromiografia de superfície. O estudo foi aprovado pelo comitê de ética local (CAAE 56102016.4.0000.5440) e registrado no Registro Brasileiro de Ensaios Clínicos (RBR-8gfv5i).

\section{Resultados}

Uma regressão linear mista foi realizada, com $p<0,05$ adotado. Não houve diferenças significativas para os desfechos primários após 8 semanas de tratamento e aos 3 meses de follow-up ( $p>0,05)$. Para os desfechos secundários, observou-se uma redução da amplitude da atividade eletromiográfica dos músculos escaleno anterior e trapézio superior nos últimos estágios do CCFT ( $p \leq 0,01)$ e dos músculos escaleno anterior e esplênio da cabeça durante o teste de resistência $(p \leq 0,04)$ no grupo intervenção após 8 semanas.

\section{Conclusão}

A realização de exercícios craniocervicais não é superior ao placebo para reduzir frequência e intensidade das crises de migrânea. Entretanto, os exercícios promoveram uma melhor ativação dos músculos cervicais durante o CCFT e o teste de resistência.

Palavras-chave: Migrânea, Dor cervical, Exercícios craniocervicais, Eletromiografia. 